Cellular Physiology
and Biochemistry and Biochemistry Published online: May 03,2016

Accepted: March 30, 2016

This article is licensed under the tional License (CC BY-NC-ND) Creative Commons Attribution-NonCommercial-NoDerivatives 4.0 International License (CC BY-NC-ND) (http://www.karger.com/Services/OpenAccessLicense). Usage and distribution for commercial purposes as well as any distribution of modified material requires written permission.
(C) 2016 The Author(s)

\title{
Effect of Lysosomotropic Polyamineoxidase Inhibitor MDL-72527 on Platelet Activation
}

\author{
Guoxing Liua,b Hang Cao ${ }^{a, b}$ Guilai Liua,b David Heinzmanna Hong Chen ${ }^{a, b}$ \\ Anja T. Umbach ${ }^{\mathrm{a}, \mathrm{b}}$ Meinrad Gawaz ${ }^{\mathrm{a}}$ Florian Lang ${ }^{\mathrm{a}, \mathrm{b}}$
}

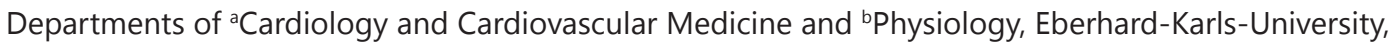
Tuebingen, Germany

\section{Key Words}

Collagen related peptide, platelet activation - Platelet degranulation, integrin activation, cytosolic $\mathrm{Ca}^{2+}$ concentration $\bullet$ Reactive oxygen species $\bullet$ Phosphatidylserine translocation

\begin{abstract}
Background/Aims: The polyamine oxidase inhibitor MDL-72527 (N1,N4-bis(2,3-butadienyl)-1,4butanediamine) were expected to increase the abundance of spermine, a powerful inhibitor of platelet activation. Nothing is known, however, on the sensitivity of platelet function and survival to MDL-72527 exposure. The present study thus explored whether MDL-72527 modifies function and survival of platelets without and with platelet activation by collagen related peptide (CRP). Methods: Platelets isolated from wild-type mice were exposed for 30 minutes to MDL-72527 (100 $\mu \mathrm{M})$ with or without subsequent activation with CRP $(2-5 \mu \mathrm{g} / \mathrm{ml})$. Flow cytometry was employed to estimate cytosolic $\mathrm{Ca}^{2+}$-activity $\left(\left[\mathrm{Ca}^{2+}\right]_{\mathrm{i}}\right)$ from Fluo-3 fluorescence, platelet degranulation from P-selectin abundance, integrin activation from $\alpha_{\text {IIb }} \beta_{3}$ integrin abundance, generation of reactive oxygen species (ROS) from DCFDA fluorescence, phospholipid scrambling of the cell membrane from annexin-V-binding, platelet volume from forward scatter and aggregation utilizing staining with CD9-APC and CD9-PE. Results: In the absence of CRP, exposure of platelets to MDL-72527 did not significantly modify $\left[\mathrm{Ca}^{2+}\right]_{i}$ P-selectin abundance, $\alpha_{\mathrm{mb}} \beta_{3}$ integrin abundance, ROS, annexin- $\mathrm{V}$ binding, and forward scatter. The addition of $2-5 \mu \mathrm{g} / \mathrm{ml}$ CRP was followed by significant increase of $\left[\mathrm{Ca}^{2+}\right]_{i^{\prime}} \mathrm{P}$-selectin abundance, $\alpha_{\mathrm{Ib}} \beta_{3}$ integrin activation, ROS abundance, annexin-V-binding, and aggregation as well as a significant decrease of forward scatter, all effects significantly blunted or virtually abolished in the presence of MDL-72527. Conclusions: MDL-72527 is a powerful inhibitor of platelet activation, apoptosis and aggregation.
\end{abstract}

(C) 2016 The Author(s)

Published by S. Karger AG, Basel

\section{Introduction}

N1,N4-bis(2,3-butadienyl)-1,4-butanediamine (MDL-72527), a lysosomotropic compound, is a strong inhibitor of spermine degrading polyamine oxidase [1-3]. Spermine is a powerful inhibitor of platelet aggregation [4-7], which contributes to primary hemostasis

Florian Lang

KARGER 
following vascular injury, to acute thrombotic occlusion following atherosclerotic plaque rupture $[8,9]$, and to arterial thrombosis, vascular inflammation and atherogenesis $[8,10]$. Platelet activation involves increase of cytosolic $\mathrm{Ca}^{2+}$ concentration $\left(\left[\mathrm{Ca}^{2+}\right]_{\mathrm{i}}\right)[11]$, resulting from $\mathrm{Ca}^{2+}$ release from intracellular stores [12] and subsequent opening of the $\mathrm{Ca}^{2+}$ releaseactivated channel (CRAC) Orai1 (CRACM1) [11, 13-16].

To the best of our knowledge, nothing is known about an effect of MDL-72527 on platelet function. The present study thus explored whether MDL-72527 modifies the effect of collagen related peptide on $\mathrm{Ca}^{2+}$ entry, activation, and apoptosis of blood platelets.

\section{Materials and Methods}

\section{Mice}

All animal experiments were conducted according to the German law for the welfare of animals and were approved by the authorities of the state of Baden-Württemberg (Regierungspräsidium). Experiments were performed with blood platelets isolated from wild type mice. The mice had free access to water and control chow (Ssniff, Soest, Germany).

\section{Preparation of mouse platelets}

Platelets were obtained from 10- to 12-week-old mice of either sex. The mice were anesthetized and $800 \mu \mathrm{l}$ blood was drawn from the retro-orbital plexus into tubes with $200 \mu \mathrm{l}$ acid-citrate-dextrose buffer before the mice were sacrificed [17]. Platelet rich plasma (PRP) was obtained by centrifugation at $260 \mathrm{~g}$ for 5 minutes. Afterwards PRP was centrifuged at $640 \mathrm{~g}$ for 5 minutes to pellet the platelets. Where necessary apyrase $\left(0.02 \mathrm{U} / \mathrm{ml}\right.$; Sigma-Aldrich) and prostaglandin $\mathrm{I}_{2}(0.5 \mu \mathrm{M}$; Calbiochem $)$ were added to the PRP to prevent activation of platelets during isolation. After two washing steps the pellet of washed platelets was re-suspended in modified Tyrode-HEPES buffer ( $\mathrm{pH} 7.4$, supplemented with $1 \mathrm{mM} \mathrm{CaCl}_{2}$ ). Where indicated, CRP (kindly provided by R. Farndale, University of Cambridge, Cambridge, UK) was added.

Cytosolic calcium

For the measurement of the cytosolic $\mathrm{Ca}^{2+}$ concentration the platelet preparation was washed once in Tyrode buffer ( $\mathrm{pH}$ 7.4), stained with $3 \mu \mathrm{M}$ Fluo-3AM (Biotinium, USA) in the same buffer and incubated at $37^{\circ} \mathrm{C}$ for 30 minutes. Following the indicated experimental treatment, relative fluorescence was measured utilizing a BD FACS Calibur (BD Biosciences, Heidelberg, Germany) [18].

\section{$P$-selectin and activated integrin abundance}

Fluorophore-labeled antibodies were utilized for the detection of P-selectin expression (Wug.E9FITC) and the active form of $\alpha_{\mathrm{II}} \beta_{3}$ integrin (JON/A-PE). Washed mouse platelets $\left(1 \times 10^{6}\right)$ were suspended in modified Tyrode buffer ( $\mathrm{pH} 7.4$ ) containing $1 \mathrm{mM} \mathrm{CaCl}_{2}$ and antibodies (1:10 dilution) and subsequently subjected to the respective treatments and for the indicated time periods at room temperature (RT). The reaction was stopped by addition of PBS and the samples were immediately analyzed on a BD FACS Calibur.

\section{Reactive oxygen species}

The abundance of reactive oxygen species (ROS) was determined utilizing $2^{\prime}, 7^{\prime}$-dichlorodihydrofluorescein diacetate (DCFDA). To load the platelets, DCFDA (Sigma, Schnelldorf, Germany) was added to the cell suspension at a final concentration of $10 \mu \mathrm{M}$. Following the indicated experimental treatments, fluorescence was measured by flow cytometry utilizing a BD FACS Calibur (BD Biosciences, Heidelberg, Germany).

\section{Phosphatidylserine exposure and forward scatter}

Phosphatidylserine exposure was determined in platelets with and without 10 minutes CRP treatment. To this end, the platelet preparation was centrifuged at $660 \mathrm{~g}$ for 5 minutes followed by washing once with Tyrode buffer (pH 7.4) with $1 \mathrm{mM} \mathrm{CaCl}_{2}$, staining with 1:20 dilution of Annexin-V FITC (Mabtag, Germany) in Tyrode buffer ( $\mathrm{pH} 7.4$ ) with $2 \mathrm{mM} \mathrm{CaCl}_{2}$ and incubation at $37^{\circ} \mathrm{C}$ for 30 minutes. Annexin-V binding reflecting surface exposure of phosphatidylserine was evaluated by flow cytometry utilizing a BD FACS Calibur. In parallel, the forward scatter (FSC) of the platelets was determined by flow cytometry as a measure of platelet size.

\section{KARGER}


Platelet aggregation

Aggregation was determined utilizing flow cytometry as previously described [19]. To this end platelets were labeled with CD9-APC and CD9-PE monoclonal antibodies (1:100 dilution, Abcam) for 15 minutes at room temperature. Following incubation, differently labeled samples were washed twice, mixed 1:1, and incubated in $100 \mu \mathrm{M}$ MDL-72527 (Sigma, Germany) for $30 \mathrm{~min}$ at $37^{\circ} \mathrm{C}$. Pre-incubated platelets were activated with $2 \mu \mathrm{g} / \mathrm{ml}$ collagen related peptide at $37^{\circ} \mathrm{C}$ while shaking at $1000 \mathrm{rpm}$. The samples were measured utilizing a BD FACS Calibur (BD Biosciences, Heidelberg, Germany). For quantification, a quadrant was set in the dot plot of respective channels on non-stimulated platelets. The appearance of double-colored events in the upper right quadrant (Q2) was quantified as percentage of total amount of labeled events $(\mathrm{Q} 1+\mathrm{Q} 2+\mathrm{Q} 4)$ at every time point analyzed.

\section{Statistical analysis}

Data are provided as means \pm SEM; $n$ represents the number of independent experiments. All data were tested for significance using ANOVA with Tukey's test as post-test or unpaired student's t-test as appropriate. Results with $p<0.05$ were considered statistically significant.

\section{Results}

The present study explored whether polyamine oxidase inhibitor N1,N4-bis(2,3butadienyl)-1,4-butanediamine (MDL-72527) modifies platelet function in the absence and presence of platelet activator collagen related peptide (CRP). To this end, murine platelets were isolated from wild type mice and exposed for $30 \mathrm{~min}$ to $100 \mu \mathrm{M}$ MDL-72527 without and with CRP treatment $(2-5 \mu \mathrm{g} / \mathrm{ml})$.

Fluo-3 fluorescence was determined as a measure of cytosolic $\mathrm{Ca}^{2+}$ concentration $\left(\left[\mathrm{Ca}^{2+}\right]_{\mathrm{i}}\right)$. As illustrated in Fig. $1 \mathrm{~A}$ and $\mathrm{C}$, prior to CRP treatment $\left[\mathrm{Ca}^{2+}\right]_{\mathrm{i}}$ was similar in the absence and presence of MDL-72527. Treatment with CRP $(2 \mu \mathrm{g} / \mathrm{ml})$ within 100 seconds significantly increased $\left[\mathrm{Ca}^{2+}\right]_{\mathrm{i}^{\prime}}$ an effect significantly blunted in the presence of $100 \mu \mathrm{M}$ MDL-72527 (Fig. 1B and C).

P-selectin abundance on the platelet surface, taken as measure of platelet degranulation, was determined by flow cytometry utilizing specific antibodies. As illustrated in Fig. 2A and C, the P-selectin abundance was negligible at the surface of resting platelets and not significantly modified by MDL-72527 treatment. CRP $(2 \mu \mathrm{g} / \mathrm{ml})$ treatment was followed by a sharp increase of P-selectin abundance, an effect significantly blunted in the presence of $100 \mu$ M MDL-72527 (Fig. 2B and C).

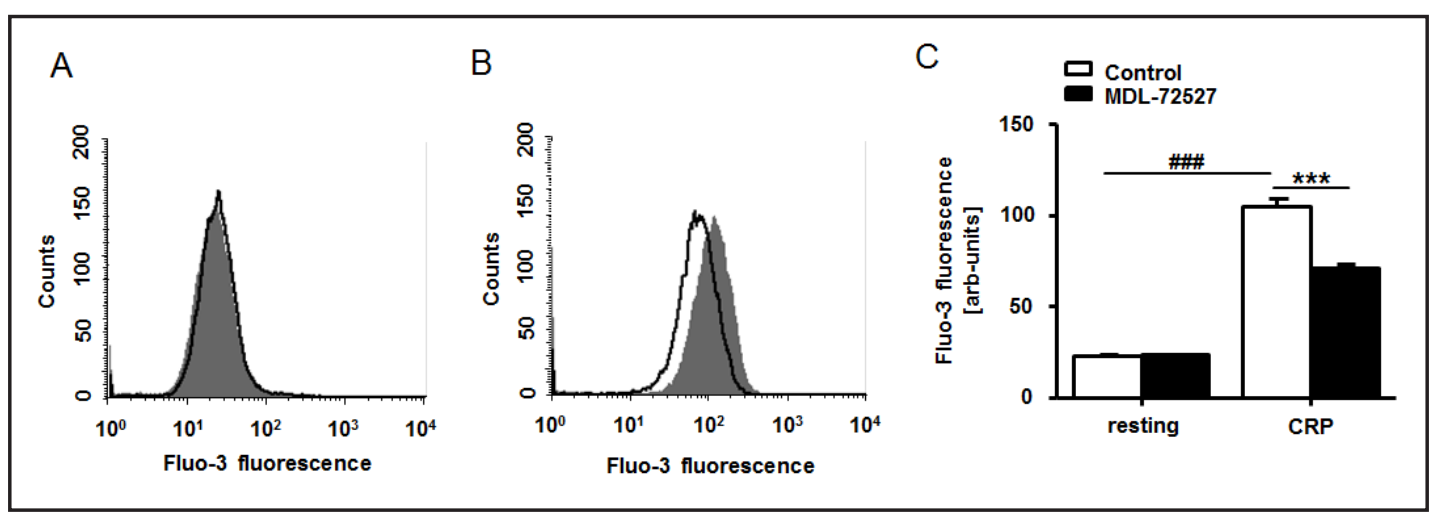

Fig. 1. MDL-72527 sensitive CRP-induced increase of cytosolic $\mathrm{Ca}^{2+}$ concentration. A,B. Original histogram overlays of Fluo-3 fluorescence reflecting cytosolic $\mathrm{Ca}^{2+}$ activity in murine platelets without (A) and with (B) a 100 seconds treatment with CRP $(2 \mu \mathrm{g} / \mathrm{ml})$ without (grey areas) and with (black lines) presence of MDL$72527(100 \mu \mathrm{M}, 30 \mathrm{~min})$. C. Arithmetic means \pm SEM $(\mathrm{n}=4)$ of Fluo-3 fluorescence reflecting cytosolic Ca ${ }^{2+}$ activity in murine platelets without (left bars) and with (right bars) a 100 seconds CRP treatment in the absence (white bars) and presence (black bars) of $100 \mu \mathrm{M}$ MDL-72527. \#\#\#( $p<0.001)$ indicates statistically significant difference from absence of CRP, ${ }^{* * *}(p<0.001)$ indicate statistically significant difference from absence of MDL-72527.

\section{KARGER}




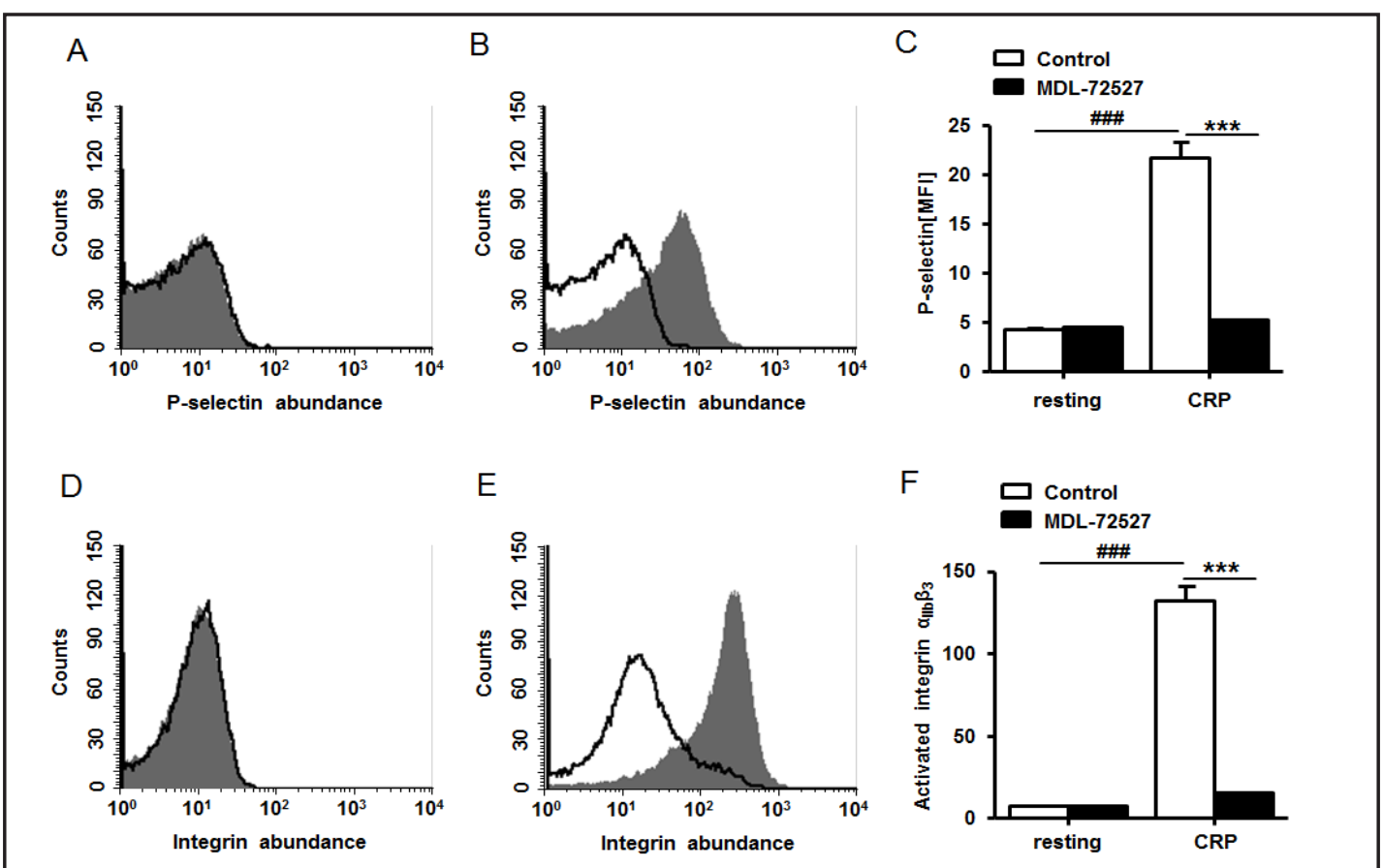

Fig. 2. MDL-72527 sensitive CRP-induced platelet degranulation and integrin $\alpha_{\mathrm{IIb}} \beta_{3}$ activation. A,B. Original histogram overlays of P-selectin related fluorescence in murine platelets without (A) and with (B) a 15 min CRP $(2 \mu \mathrm{g} / \mathrm{ml})$ treatment without (grey areas) and with (black lines) presence of MDL-72527 (100 $\mu \mathrm{M}, 30$ min). C. Arithmetic means \pm SEM $(n=4)$ of the P-selectin related fluorescence (arbitrary units) in murine platelets without (left bars) and with (right bars) a $15 \mathrm{~min}$ CRP treatment ( $2 \mu \mathrm{g} / \mathrm{ml}$ ) in the absence (white bars) and presence (black bars) of $100 \mu \mathrm{M}$ MDL-72527. D,E. Original histogram overlays of activated $\alpha_{\mathrm{IIb}} \beta_{3}$ integrin related fluorescence in murine platelets without (D) and with (E) a $15 \mathrm{~min} \mathrm{CRP}(2 \mu \mathrm{g} / \mathrm{ml})$ treatment without (grey areas) and with (black lines) presence of MDL-72527 (100 $\mu \mathrm{M}, 30 \mathrm{~min})$. F. Arithmetic means \pm SEM $(n=4)$ of activated $\alpha_{\mathrm{Ib}} \beta_{3}$ integrin related fluorescence (arbitrary units) in murine platelets without (left bars) and with (right bars) a $15 \mathrm{~min}$ CRP treatment $(2 \mu \mathrm{g} / \mathrm{ml}$ ) in the absence (white bars) and presence (black bars) of $100 \mu \mathrm{M}$ MDL-72527. \#\#\#(p<0.001) indicates statistically significant difference from absence of CRP, ${ }^{* * *}(p<0.001)$ indicate statistically significant difference from absence of MDL-72527.

The abundance of active integrin $\alpha_{\mathrm{IID}} \beta_{3}$, another indicator of platelet activation, was again determined by flow cytometry utilizing specific antibodies. As shown in Fig. 2D and F, the abundance of active integrin $\alpha_{\mathrm{Ib}} \beta_{3}$ was again negligible at the surface of resting platelets, but was significantly increased by treatment with CRP $(2 \mu \mathrm{g} / \mathrm{ml})$. Again, the effect of CRP on the abundance of active integrin $\alpha_{\mathrm{IIb}} \beta_{3}$ was significantly blunted in the presence of $100 \mu \mathrm{M}$ MDL72527 (Fig. 2E and F).

The abundance of reactive oxygen species (ROS) was quantified utilizing DCFDA fluorescence. As shown in Fig. 3A and C, the ROS abundance was low in resting platelets. Following a $2 \mu \mathrm{g} / \mathrm{ml}$ CRP treatment, ROS generation was significantly increased, an effect significantly blunted in the presence of MDL-72527 treatment (Fig. 3B and C).

Annexin-V-binding was taken as evidence for cell membrane scrambling with phosphatidylserine translocation to the platelet surface. As illustrated in Fig. $4 \mathrm{~A}$ and $\mathrm{C}$, the percentage of annexin- $V$ positive platelets was again negligible in untreated platelets, irrespective of the presence of MDL-72527. CRP ( $5 \mu \mathrm{g} / \mathrm{ml})$ within $10 \mathrm{~min}$ significantly enhanced the percentage of annexin- $\mathrm{V}$ binding platelets, an effect again significantly blunted in the presence of $100 \mu \mathrm{M}$ MDL-72527 (Fig. 4B and C).

Forward scatter determined by flow cytometry was taken as a measure of platelet volume. As illustrated in Fig. 4D and F, prior to stimulation with CRP, forward scatter was similar in the absence and presence of MDL-72527. CRP ( $5 \mu \mathrm{g} / \mathrm{ml})$ treatment within $10 \mathrm{~min}$ was followed by 


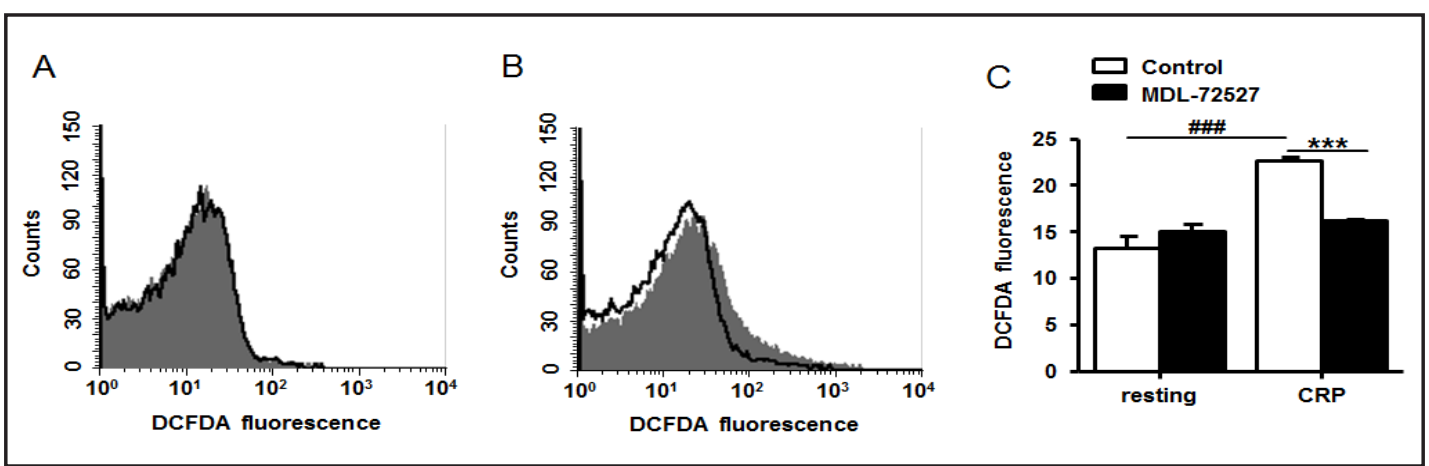

Fig. 3. MDL-72527 sensitive CRP-induced increase of reactive oxygen species. A,B. Original histogram overlays of DCFDA fluorescence reflecting ROS abundance (arbitrary units) in murine platelets without (A) and with

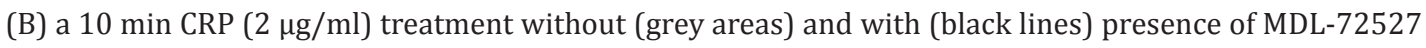
$(100 \mu \mathrm{M}, 30 \mathrm{~min})$. C. Arithmetic means \pm SEM $(\mathrm{n}=4)$ of DCFDA fluorescence reflecting ROS abundance (arbitrary units) in murine platelets without (left bars) and with (right bars) a 10 min treatment with $2 \mu \mathrm{g} / \mathrm{ml}$ CRP in the absence (white bars) and presence (black bars) of $100 \mu \mathrm{M}$ MDL-72527. \#\#\# $(p<0.001)$ indicates statistically significant difference from absence of CRP, ${ }^{* * *}(p<0.001)$ indicate statistically significant difference from absence of MDL-72527.

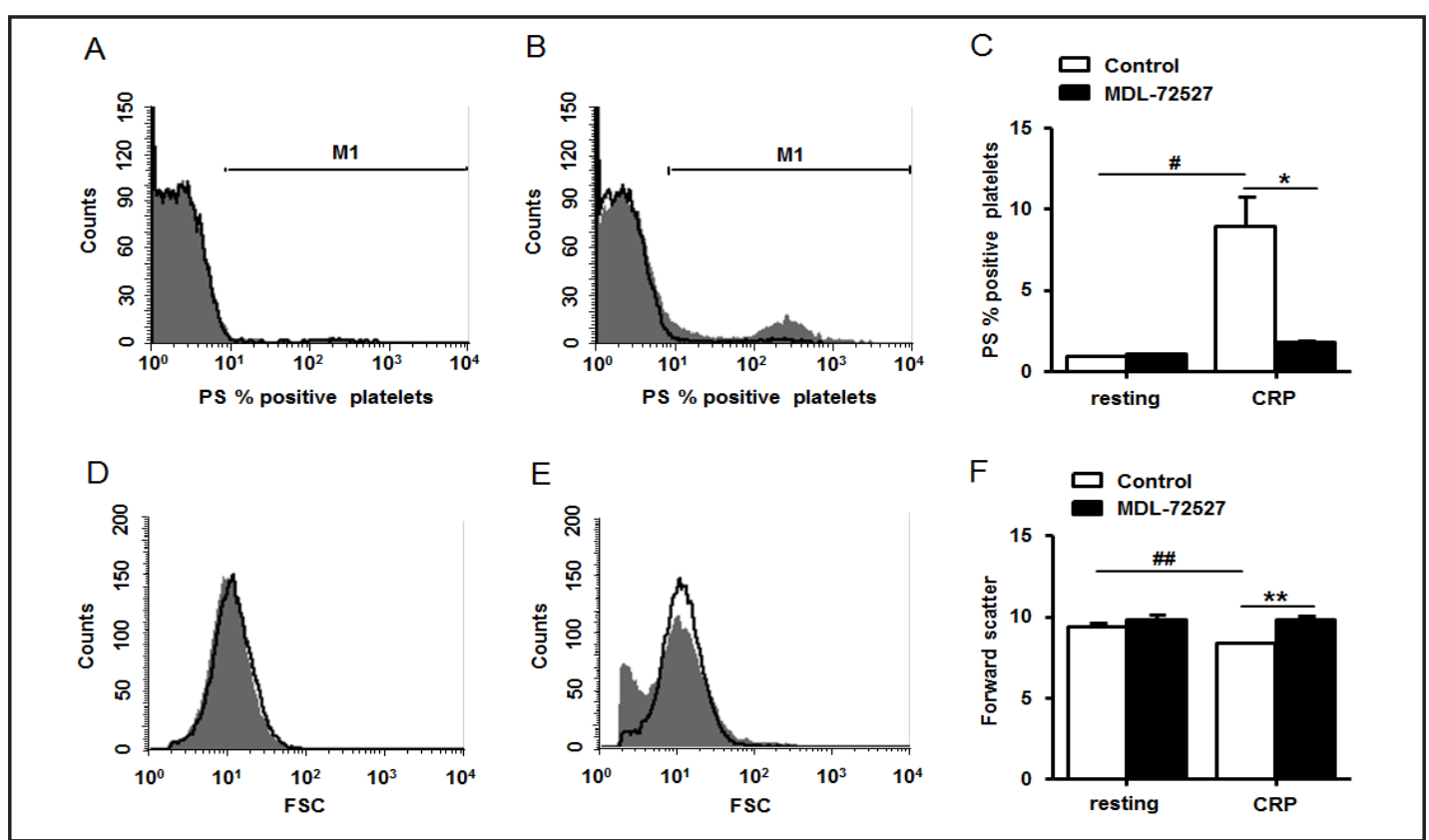

Fig. 4. MDL-72527 sensitive CRP-dependent cell membrane scrambling and cell volume. A,B. Original histogram overlays of annexin-V-binding reflecting phosphatidylserine abundance at the surface of murine platelets without (A) and with (B) a 10 min treatment with CRP (5 $\mu \mathrm{g} / \mathrm{ml}$ ) without (grey areas) and with (black lines) presence of MDL-72527 (100 $\mu$ M, $30 \mathrm{~min})$. C. Arithmetic means \pm SEM $(n=4)$ of the percentage of annexin-V-binding murine platelets in the absence (white bars) and presence (black bars) of $100 \mu \mathrm{M}$ MDL-72527 without (left bars) and with (right bars) a $10 \mathrm{~min}$ CRP treatment (5 $\mathrm{\mu g} / \mathrm{ml}$ ). D,E. Original histogram overlays of forward scatter reflecting cell volume of murine platelets without (D) and with (E) a $10 \mathrm{~min}$ treatment with CRP (5 $\mathrm{g} / \mathrm{ml})$ without (grey areas) and with (black lines) presence of MDL$72527(100 \mu \mathrm{M}, 30 \mathrm{~min})$. F. Arithmetic means \pm SEM $(\mathrm{n}=4)$ of forward scatter reflecting cell volume of murine platelets without (left bars) and with (right bars) a $10 \mathrm{~min}$ CRP treatment ( $5 \mu \mathrm{g} / \mathrm{ml}$ ) in the absence (white bars) and presence (black bars) of $100 \mu \mathrm{M}$ MDL-72527. \# $(p<0.05) \# \#(p<0.01)$ indicates statistically significant difference from absence of CRP, ${ }^{*}(p<0.05)^{* *}(p<0.01)$ indicate statistically significant difference from absence of MDL-72527.

\section{KARGER}


A
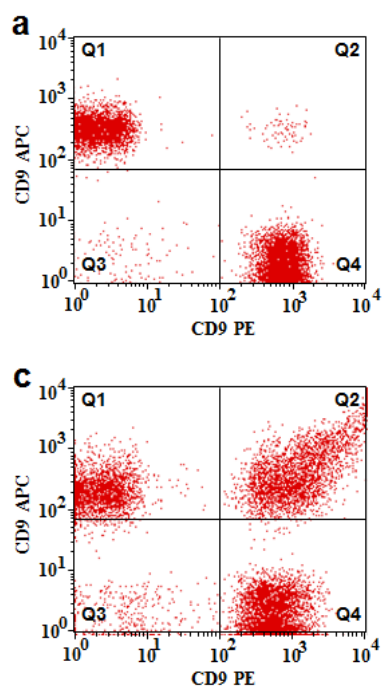
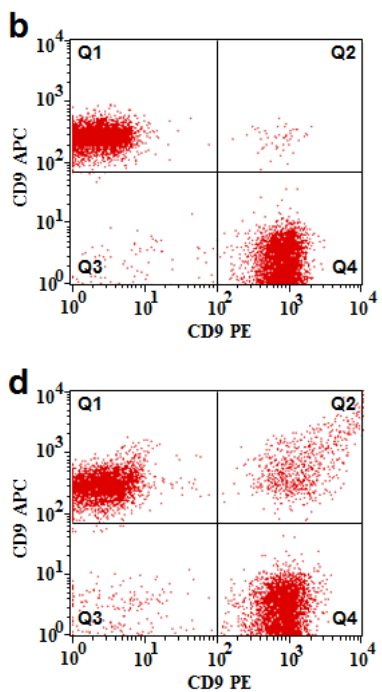

B

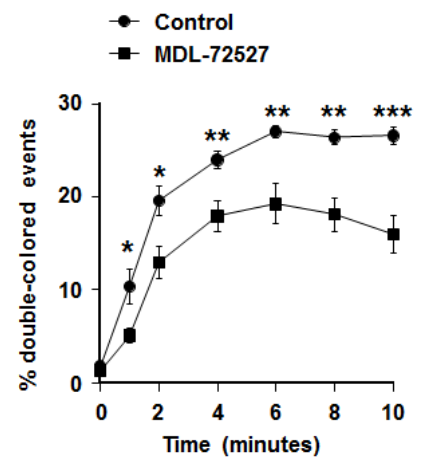

Fig. 5. MDL-72527 sensitive CRP-induced platelet aggregation. A. Original dot blots reflecting platelet aggregation without $(\mathrm{a}, \mathrm{b})$ and with $(\mathrm{c}, \mathrm{d}) 10 \mathrm{~min}$ CRP $(2 \mu \mathrm{g} / \mathrm{ml})$ treatment in the absence $(\mathrm{a}, \mathrm{c})$ and presence $(\mathrm{b}, \mathrm{d})$ of MDL-72527 (100 $\mu \mathrm{M}, 30 \mathrm{~min})$. B. Arithmetic means \pm SEM $(\mathrm{n}=6)$ of platelet aggregation without (black circles) and with (black squares) prior MDL-72527 $(100 \mu \mathrm{M})$ treatment as a function of time after addition of CRP $(2 \mu \mathrm{g} / \mathrm{ml}) .{ }^{*}(p<0.05){ }^{* *}(p<0.01){ }^{* * *}(p<0.001)$ indicate statistically significant difference from absence of MDL-72527.

a significant decrease of forward scatter in the absence, but not in the presence of $100 \mu \mathrm{M}$ MDL72527 (Fig. 4E and F).

In order to quantify platelet aggregation, platelets were labeled with two distinct dyes and the coincidence of the two dyes estimated by flow cytometry. As illustrated in Fig. 5, aggregation of resting platelets was similarly low in MDL-72527 treated and untreated platelets. CRP (2 $\mu \mathrm{g} / \mathrm{ml}$ ) treatment within a few min significantly increased the platelet aggregation, an effect significantly blunted by MDL-72527 treatment.

\section{Discussion}

The present observations uncover a novel effect of the polyamine oxidase inhibitor MDL-72527 (N1,N4-bis(2,3-butadienyl)-1,4-butanediamine), i.e. suppression of platelet activation and apoptosis following treatment with collagen related peptide (CRP). In the absence of CRP, MDL-72527 did not appreciably modify the tested platelet properties. In contrast, MDL-72527 significantly blunted or even virtually abrogated the effect of CRP on platelet cytosolic $\mathrm{Ca}^{2+}$ concentration $\left(\left[\mathrm{Ca}^{2+}\right]_{\mathrm{i}}\right)$, degranulation, integrin activation, oxidative stress, cell membrane scrambling, cell shrinkage, and aggregation. Accordingly, MDL-72527 attenuates the procoagulant function of platelets, which is instrumental for hemostasis [20].

In theory, the effects of MDL-72527 could be explained by inhibition of polyamine oxidase which could be expected to enhance the abundance of spermine, a powerful inhibitor of platelet aggregation [4-7]. The present observations do, however, not rule out that MDL72527 modifies platelet activation and survival through mechanisms other than decreased spermine degradation.

Signaling leading to platelet activation and apoptosis as well as and thrombus formation involves increase of $\left[\mathrm{Ca}^{2+}\right]_{\mathrm{i}}[14,21]$ and the negative effects of MDL-72527 on activation and cell membrane scrambling could have been secondary to its effect on $\left[\mathrm{Ca}^{2+}\right]_{\mathrm{i}^{*}}$ The increase 
of $\left[\mathrm{Ca}^{2+}\right]_{\mathrm{i}}$ following CRP treatment could in part be due to oxidative stress. Along those lines, MDL-72527 blunted the increase of reactive oxygen species (ROS) following CRP treatment, which could thus contribute to or even account for the attenuation of platelet activation and apoptosis by MDL-72527.

Platelet activation by increased $\left[\mathrm{Ca}^{2+}\right]_{\mathrm{i}}$ fosters the development of arterial thrombosis [11]. Increased $\left[\mathrm{Ca}^{2+}\right]_{\mathrm{i}}$ further triggers platelet apoptosis characterized by phospholipid scrambling of the cell membrane with translocation of phosphatidylserine to the platelet surface [10, 22-24]. The inhibition of CRP-induced $\mathrm{Ca}^{2+}$ entry may thus contribute or even account for the inhibition of CRP-induced phosphatidylserine exposure in the presence of MDL-72527. Phosphatidylserine exposure at the platelet surface triggers the formation of thrombin, which potentiates platelet activation [22-25]. Phosphatidylserine exposure mediates the binding of platelets to macrophages with subsequent platelet phagocytosis [26]. Platelet activation and phosphatidylserine exposure stimulate platelet aggregation, which was again slightly, but significantly blunted by MDL-72527.

In conclusion, polyamine oxidase inhibitor MDL-72527 is a powerful inhibitor of CRPinduced increase $\left[\mathrm{Ca}^{2+}\right]_{\mathrm{i}}$, oxidative stress, degranulation, integrin activation, cell membrane scrambling, shrinkage, and aggregation in and of platelets, thus suppressing platelet activation and apoptosis.

\section{Acknowledgements}

We thank Efi Faber for providing technical assistance as well as Tanja Loch for meticulous preparation of the manuscript. This study was supported by the Deutsche Forschungsgemeinschaft - Klinische Forschergruppe [DFG-KFO 274] 'Platelets-Molecular Mechanisms and Translational Implications', as well as the Tuebingen Platelet Investigative Consortium (TuePIC), and the Open Access Publishing Fund of Tuebingen University.

\section{Disclosure Statement}

The authors of this manuscript state that they have no conflicts of interest to declare.

\section{References}

1 Agostinelli E, Tempera G, Viceconte N, Saccoccio S, Battaglia V, Grancara S, Toninello A, Stevanato R: Potential anticancer application of polyamine oxidation products formed by amine oxidase: a new therapeutic approach. Amino Acids 2010;38:353-368.

2 Seiler N: How important is the oxidative degradation of spermine?: minireview article. Amino Acids 2004;26:317319.

3 Seiler N, Duranton B, Raul F: The polyamine oxidase inactivator MDL 72527. Prog Drug Res 2002;59:1-40.

4 de la Pena NC, Sosa-Melgarejo JA, Ramos RR, Mendez JD: Inhibition of platelet aggregation by putrescine, spermidine, and spermine in hypercholesterolemic rabbits. Arch Med Res 2000;31:546-550.

5 Israels SJ, Gerrard JM, Robinson P: Differential effects of spermine on aggregation, inositol phosphate formation and protein phosphorylation in human platelets in response to thrombin, arachidonic acid and lysophosphatidic acid. Biochim Biophys Acta 1986;883:247-252.

6 Joseph S, Krishnamurthi S, Kakkar VV: Effect of the polyamine-spermine on agonist-induced human platelet activation--specific inhibition of "aggregation-independent" events induced by thrombin, but not by collagen, thromboxane mimetic, phorbol ester or calcium ionophore. Thromb Haemost 1987;57:191-195.

7 Via LD, Francesconi M, Mazzucato M, Pradella P, De Marco L, Vecchia FD, Rascio N, Deana R: On the mechanism of the spermine-exerted inhibition on alpha-thrombin-induced platelet activation. Thromb Res 2000;98:59-71.

8 Gawaz M: Role of platelets in coronary thrombosis and reperfusion of ischemic myocardium. Cardiovasc Res 2004;61:498-511.

9 Borst O, Schmidt EM, Munzer P, Schonberger T, Towhid ST, Elvers M, Leibrock C, Schmid E, Eylenstein A, Kuhl D, May AE, Gawaz M, Lang F: The serum- and glucocorticoid-inducible kinase 1 (SGK1) influences platelet calcium signaling and function by regulation of Orai1 expression in megakaryocytes. Blood 2012;119:251-261. 


\section{Cellular Physiology Cell Physiol Biochem 2016;38:1695-1702 \begin{tabular}{l|l} 
DOI: 10.1159/000443108 & $\begin{array}{l}\text { O 2016 The Author(s). Published by S. Karger AG, Basel } \\
\text { www.karger.com/cpb }\end{array}$
\end{tabular} \\ Liu et al.: MDL-72527 Sensitive Platelet Function}

10 Borst O, Munzer P, Gatidis S, Schmidt EM, Schonberger T, Schmid E, Towhid ST, Stellos K, Seizer P, May AE, Lang F, Gawaz M: The inflammatory chemokine CXC motif ligand 16 triggers platelet activation and adhesion via CXC motif receptor 6-dependent phosphatidylinositide 3-kinase/Akt signaling. Circ Res 2012;111:1297-1307.

11 Bergmeier W, Stefanini L: Novel molecules in calcium signaling in platelets. J Thromb Haemost 2009;7:S187-190.

12 Varga-Szabo D, Braun A, Nieswandt B: Calcium signaling in platelets. J Thromb Haemost 2009;7:1057-1066.

13 Braun A, Varga-Szabo D, Kleinschnitz C, Pleines I, Bender M, Austinat M, Bosl M, Stoll G, Nieswandt B: Orai1 (CRACM1) is the platelet SOC channel and essential for pathological thrombus formation. Blood 2009;113:20562063.

14 Varga-Szabo D, Braun A, Nieswandt B: STIM and Orai in platelet function. Cell Calcium 2011;50:270-278.

15 Wang Y, Deng X, Gill DL: Calcium signaling by STIM and Orai: intimate coupling details revealed. Sci Signal 2010;3:e42.

16 Liu G, Liu G, Alzoubi K, Chatterjee M, Walker B, Munzer P, Luo D, Umbach AT, Elvira B, Chen H, Voelkl J, Foller M, Mak TW, Borst O, Gawaz M, Lang F: CD44 sensitivity of platelet activation, membrane scrambling and adhesion under high arterial shear rates. Thromb Haemost 2015;115:

17 Pelzl L, Fakhri H, Umbach AT, Gawaz M, Paulmichl M, Lang F: Sgk1 sensitive pendrin expression in murine platelets. Cell Physiol Biochem 2013;32:210-220.

18 Towhid ST, Schmidt EM, Tolios A, Munzer P, Schmid E, Borst O, Gawaz M, Stegmann E, Lang F: Stimulation of platelet death by vancomycin. Cell Physiol Biochem 2013;31:102-112.

19 De Cuyper IM, Meinders M, van de Vijver E, de Korte D, Porcelijn L, de Haas M, Eble JA, Seeger K, Rutella S, Pagliara D, Kuijpers TW, Verhoeven AJ, van den Berg TK, Gutierrez L: A novel flow cytometry-based platelet aggregation assay. Blood 2013;121:e70-80.

20 Lhermusier T, Chap H, Payrastre B: Platelet membrane phospholipid asymmetry: from the characterization of a scramblase activity to the identification of an essential protein mutated in Scott syndrome. J Thromb Haemost 2011;9:1883-1891.

21 Lang F, Munzer P, Gawaz M, Borst O: Regulation of STIM1/Orai1-dependent Ca2+ signalling in platelets. Thromb Haemost 2013;110:925-930.

22 Harper MT, Poole AW: Store-operated calcium entry and non-capacitative calcium entry have distinct roles in thrombin-induced calcium signalling in human platelets. Cell Calcium 2011;50:351-358.

23 Mahaut-Smith MP: A role for platelet TRPC channels in the Ca2+ response that induces procoagulant activity. Sci Signal 2013;6:pe23.

24 Mushtaq M, Nam TS, Kim UH: Critical role for CD38-mediated Ca2+ signaling in thrombin-induced procoagulant activity of mouse platelets and hemostasis. J Biol Chem 2011;286:12952-12958.

25 Wolfs JL, Comfurius P, Rasmussen JT, Keuren JF, Lindhout T, Zwaal RF, Bevers EM: Activated scramblase and inhibited aminophospholipid translocase cause phosphatidylserine exposure in a distinct platelet fraction. Cell Mol Life Sci 2005;62:1514-1525.

26 Badlou BA, Wu YP, Smid WM, Akkerman JW: Platelet binding and phagocytosis by macrophages. Transfusion 2006;46:1432-1443. 